International Journal of Research in Nursing 1 (1): 17-20, 2010

ISSN 1949-0194

(C) 2010 Science Publications

\title{
Assessment of Predicting Risk Factors for Cesarean Complication Development in Tikrit City Hospitals
}

\author{
${ }^{1}$ Nabila K. Yaaqoub, ${ }^{1}$ Enas M. Yassen and ${ }^{2}$ Ruqiya S. Tawfeek \\ ${ }^{1}$ Department of Gynecology and Obstetric, Faculty of Medicine \\ ${ }^{2}$ Department of Community Medicine, \\ Tikrit Medical College, P.O. Box 42, Tikrit, Salahudin, Iraq
}

\begin{abstract}
Problem statement: A cesarean birth happens through an incision in the abdominal wall and uterus In November of 2005, the Centers for Disease Control and prevention (CDC) reported the national cesarean birth rate was the highest ever at $29.1 \%$, which is over a quarter of all deliveries. This means that over 1 in 4 women will experience a cesarean delivery. With any major surgical procedure, there are risks involved. It is important to know and understand your risks before a cesarean procedure, Approach: Descriptive study was carried from 1st March to end of October 2009, 200 cases attending Tikrit teaching hospital and 2 private hospitals in Tikrit city that were developing complications after cesarean section during time of the study were enrolled in this study. Results: The study reviled that half of study population from age group 20-34 years, 36.5\% were developed complications after C/S. it was founded that 36.5\% developed wound infections, $31.5 \%$ complained from post partum hemorrhage $17.5 \%$ of them of secondary type and $14 \%$ of primary type. And 6, 7.5 and $1 \%$ developed paralytic illus, DVT, death respectively and 34\% occurred within first week after $\mathrm{C} / \mathrm{S}$ and $8 \%$ within operation. Conclusion: Wound infection and hemorrhage are the most frequent complications that happened after cesarean section and about third of patients with complication had previous complication.
\end{abstract}

Key words: Cesarean section complication

\section{INTRODUCTION}

Cesarean delivery refers an operation that is performed to deliver a baby via the trans-abdominal rout (Fuantes, 1997). Cesarean delivery has been documented in ancient Egypt, Asia and Europe (Ash Morga and Baker, 2006). Written reports of cesarean section and survival not reported till late 1700s and early 1800s (Hill .A. 2010). The first cesarean on a life women is thought to that of the wife of Jacob Nufer, a sixteenth-century Swiss pig farmer, she was saved by the procedure (Ash Morga and Baker, 2006).

The name cesarean derives from the Roman law included in the region of the cesarean and not as is commonly thought to the delivery of the infant Julius Caesar (Lamisden and Hideey, 2000). Most hospitals reports a $10-35 \%$ of birth rate and its use has increased significantly over the past year and numerous attempts are underway to decrease the cesarean births in some countries such as USA (Fuantes, 1997). By the twenty century, the classical (Medline-vertical uterine incision) operation had become widespread for the obstructed labor and placenta previa (Ash Morga and Baker, 2006). Which is associated with high blood loss and risk of uterine rapture (Fuantes, 1997). When Murrokurr introduced the concept of labor segment operation in the 1920s. The profession was derisive (Ash Morga and Baker, 2006).

Labor, malposition, prolapsed cord, multiple gestation, fetal distress, malpresentation, medical and surgical indications, obstetrical complications and previous $\mathrm{C} / \mathrm{S}$ while indication for classical $\mathrm{C} / \mathrm{S}$ are, pre-term labor placenta previa, transverse lie with back posterior large cervical fibroid, sever adhesions in lower segment, postmortem C/S (Ash Morga and Baker, 2006).

In many instances $\mathrm{C} / \mathrm{S}$ deliveries are considered to be life saving procedure for both the mother and the infant. However similar to all surgical procedure, $\mathrm{C} / \mathrm{S}$ may be associated with increased maternal morbidity and mortality as compared to vaginal delivery (Koroukian and Rimm, 2000; Annibale et al., 1995). So the aim of study is:

Corresponding Author: Nabila K. Yaaqoub, Department of Gynecology and Obstetric, Faculty of Medicine, University of Tikrit P.O. Box 42, Tikrit, Salahudin, Iraq 
To estimate the rate of different types of complications among cesarean section

To identify the predispososing risks factors for development of cesarean section complication

To study the relation between previous and current complication

To identify the relation between antenatal care and the cesarean section complication

\section{MATERIALS AND METHODS}

Descriptive study was carried from 1st March to end of October 2009, ethical consideration like official agreement of patients were obtained from 200 cases attending Tikrit teaching hospital and 2 private hospitals in Tikrit city who were developing complications after cesarean section during time of the study were enrolled in this study and 2 recorded death cases after $\mathrm{C} / \mathrm{S}$ were included also, special questionnaire form designed for this study including information about some variables that influence complication development like demographical features, history of previous, last pregnancy types and time of complication were collected and analyzed.

\section{RESULTS}

The study reviled that half of study population from age group 20-34 years and about 59\% from rural while $54 \%$ of patients with parity $1-4$ as shown in Table 1.

Table 1: Distribution of cases according to some demographical characteristics

\begin{tabular}{lcc}
\hline Characteristics & Frequency & Percentage \\
\hline Age & & \\
$<20$ years & 23 & 11.5 \\
20-34 years & 104 & 52.0 \\
$\geq 35$ years & 73 & 36.5 \\
Address & & \\
Rural & 116 & 59.0 \\
urban & 84 & 41.0 \\
Parity & & \\
Para 0 & 31 & 15.5 \\
$1-4 \quad 109$ & 54.5 \\
$\geq 5 \quad 60 \quad 30.0$ & & \\
\hline
\end{tabular}

Table 2: distribution of cases according to previous obstetrical history

\begin{tabular}{lcc}
\hline Characteristics & Frequency & Percentage \\
\hline History of abortion & 49 & \\
Yes & 151 & 24.5 \\
No & & 75.5 \\
History of previous C/S & 76 & 38.0 \\
Yes & 124 & 62.0 \\
No & & \\
History of complication & & \\
after previous C/S & 73 & 36.5 \\
Yes & 127 & 63.5 \\
No & & \\
\hline
\end{tabular}

From Table 2, 24.5\% of patients had previous history of abortions, 38\% with history of previous caesarean sections and $36.5 \%$ were developed complications after $\mathrm{C} / \mathrm{S}$.

Regarding the obstetrical history for the last pregnancy (Table 3), it was founded that $48.5 \%$ complained from uterine contraction while $7.5,9.5 \%$ with gestational diabetes and hypertension respectively and $23 \%$ with history of uterine bleeding, $69 \%$ with anaemia and also $55 \%$ were attending the antenatal care facilities $37.3 \%$ of them reviled regular visits during the last pregnancy.

About types of complications that were happened after last C/S (Table 4) it was founded that 36.5\% developed wound infections, $31.5 \%$ complained from post partum hemorrhage $17.5 \%$ of them of secondary type and $14 \%$ of primary type. And 6, 7.5 and 1\% developed paralytic illus, DVT, death respectively while $16.5 \%$ developed other types of complications like bladder injuries, retained pack, incision hernia.

Table 3: History of last pregnancy

\begin{tabular}{llc}
\hline Characteristics & Frequency & Percentage \\
\hline History uterine contraction & & \\
Yes & 97 & 48.5 \\
No & 103 & 51.5 \\
History of gestational diabetes & 15 & 7.5 \\
Yes & 185 & 92.5 \\
No & & \\
History of uterine bleeding (APH) & & 23.0 \\
Yes & 46 & 77.0 \\
No & 154 & \\
History of hypertension & & 9.5 \\
Yes & 19 & 90.5 \\
No & 181 & \\
History of antenatal visits & & 55.0 \\
Yes & 110 & 45.0 \\
No & 90 & \\
Regular antenatal visits & & 37.3 \\
Yes & $41 / 110$ & 62.7 \\
No & $69 / 110$ & 69.0 \\
Anemia & & 31.0 \\
Yes & 138 & \\
No & 62 & \\
\hline
\end{tabular}

Table 4: types of complications after last C/S

\begin{tabular}{lcc}
\hline Type of complication & Frequency & Percentage \\
\hline Post partum hemorrhages & & \\
Primary & 28 & 14.0 \\
Secondary & 37 & 17.5 \\
Wound infection & 73 & 36.5 \\
Paralytic illus & 12 & 6.0 \\
DVT & 15 & 7.5 \\
Bladder injury & 4 & 2.0 \\
Renal failure & 2 & 1.0 \\
Retained pack & 1 & 0.5 \\
Respiratory tract infection & 3 & 1.5 \\
Urinary tract infection & 4 & 2.0 \\
More than one complications & 19 & 9.5 \\
Death & 2 & 1.0 \\
\hline
\end{tabular}




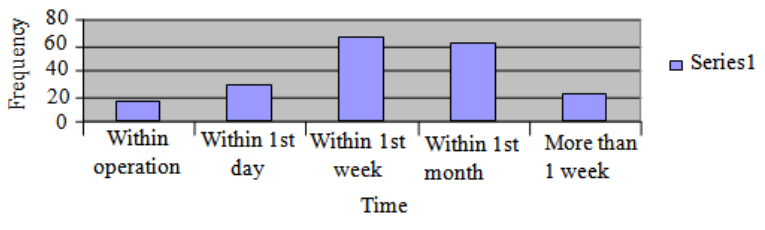

Fig. 1: Distribution of cases with complications according to time of occurrences

From Fig. 1 the time of complications development of cases were founded that $34 \%$ occurred within first week after $\mathrm{C} / \mathrm{S}$ and $8 \%$ within operation.

\section{DISCUSSION}

As more than $30 \%$ of deliveries are now by C/S (Callahon and Caughay, 2009). The risk of both early and long term complications are increased in women delivered by $\mathrm{C} / \mathrm{S}$ when compared with the outcomes after normal vaginal deliveries with risks of surgical and anesthesia (Ash Morga and Baker, 2006).

The key to successful management of postpartum complications is the identifications patient at risks and the adaptation of precautions to avoid occurrence of the problem, however in many cases complications occurs unexpectly and successful management on early recognition and adequate treatment. The risk of complications increased with previous scar, smoking, poor nutrition, excess alcohol consumption, placenta previa, chronic heart or lung diseases and use of some drugs such as CNS drugs. Some of these factors can be modified or changes (Miller et al., 1997).

Post partum hemorrhage is the most common complications of cesarean section. It defined as blood loss approximately more than $1000 \mathrm{cc}$ after cesarean section. It complicated approximately $3.9 \%$ of normal vaginal delivery and $6.4 \%$ of cesarean deliveries and accounts for approximately $35 \%$ of all maternal deaths caused by bleeding during pregnancy. The risk factors to it in $\mathrm{C} / \mathrm{S}$ are general anesthesia, chorioaminitis, preeclampsia, protracted active phase of labor, arrest of second stage of labor and Hispanic ethnicity (Arias, 1993).

Sub peritoneal hematoma is much less common than genital hematoma that occurs usually after normal vaginal delivery and $50 \%$ of them discovered immediately and half of them only present after $24 \mathrm{~h}$ (Johnson, 1999), when it should be suspected in cases of postoperative hypovulemia without external blood loss and definitive diagnosis of it by ultrasound and CT scanning (Arias, 1993). Endomyometritis is a polymicrobial ascending infection of organisms that constitute the normal vaginal of flora that infect uterine living. It affect $10-30 \%$ of cesarean deliveries, the most common microorganisms are, Gardnella vaginals, group B Streptoccoci, Echerichia coli, Bacteroids bividus and Mycoplasma. The risks factors for it are: Meconium, chorioaminitis, prolonged ruptured of $\mathrm{m}$ antibiotic membranes, frequent vaginal examination, anemia and low socioeconomic state and it prevented by prophylacticound (Callahon and Caughay, 2009; Arias, 1993; Johnson, 1999). Wound infections include cellulites and abscess are seen in $1-5 \%$ of $\mathrm{C} / \mathrm{S}$. Cellulites is suspected with local erythema around surgical site and treated by broad spectrum antibiotics. Abscess is a palpable collection within the incision and treated by incision drainage, cleaning and packing. Wound separation can occur are in the absence of infection due to fluid collection of either serum (seroma) or blood (hematoma). If fascia is also separated, this Tremel awound dehiscence (Callahon and Caughay, 2009). The incidence of superficial thrombophelibitis increases 7 times (12 per 1000 pregnancies) during postpartum period. It a painful complication hypercoagulability, it is treated with worm compresses and analgesia. It is unlikely to cause DVT or PE (Callahon and Caughay, 2009; Arias, 1993; Shearer, 1993; Lydon-Rochelle et al., 2000), DVT incidence increases $4-5$ times $(15$ per 10000 pregnancies) during postpartum period because this is the time during which a rapid rise in plasma and whole blood fibrinolytic activity occurs. The risk factors are cesarean section, obesity, use of estrogen to suppress lactation, obstetric complication (such as multiple labor, induction, prolonged labor, age less than 30 years old, difficult labor, high parity and deficiency of a natural anticoagulant activity. Pulmonary embolism occurs rarely during pregnancy, Friend and Kakkar (1970) reported an incidence of 2.7 per 1000 , but almost certainly this is a high estimate resulting from over diagnosis. In about 95\% PE is the result of DVT of ileofemoral veins and in the majority of cases, it occurs in the immediate postpartum period (Callahon and Caughay, 2009; Declerq et al., 2007; ACOG, 2000). The injury to bladder and ureter at the time of $\mathrm{C} / \mathrm{S}$ is $0.3-0.7 \%$ respectively, the risk of injury to bladder is increased three fold in repeated cesarean section previous pelvic surgery, uretric injury can rise to two or six fold when cesarean hysterectomy performed and associated with uterine extension to broad ligament and extension to broad ligament and extensive hemorrhage. The chance of dying from cesarean section is about 200/100000. The other rare complication are retained placenta, mastitis postpartum depression, maternal cardiovascular, accident which is not reported in current study. 


\section{CONCLUSION}

Nearly tow third of complication are wound infection and poor antenatal care visits with history of previous complication are the most predisposing risks factors for development of such complications.

Recommendation: Established a national health program concerned with pregnant women during antenatal visits regarding the health care of women who subjected to $\mathrm{C} / \mathrm{S}$ after section and during future pregnancies.

Improved health facilities standard to overcome morbidity and mortality that occurred from C/S.

\section{REFERENCES}

ACOG., 2000. Evaluation of cesarean delivery. ACOG, Washington, DC.

http://www.americanpregnancy.org/labornbirth/ces areanrisks.html

Annibale, D.J., T.C. Hulsey, C.L. Wagner and W.M. Southgate, 1995. Comparative neonatal morbidity of abdominal and vaginal deliveries after uncomplicated pregnancies. Arch. Pediatr. Adolesc. $\quad$ Med., 149: 862-867. http://cat.inist.fr/?aModele $=$ afficheN\&cpsidt=3609 900

Arias, F., 1993. Practical Guide to High Risk Pregnancy and Delivery. 2nd Edn., Mosby Inc., USA., ISBN: 10: 080160057X, pp: 464.

Ash Morga and P. Baker, 2006. Gynecology by Ten Teachers. 18th Edn., Oxford University Press, ISBN: 13: 9780340816622, pp: 296.

Callahon, T. and A.B. Caughay, 2009. Blue Prints Obstetrics and Gynecology. 5th Edn., Lippincoth Wiltan and William, ISBN: 13: 9780781782494 , pp: 368 .

Declerq, E.R., C. Sakala, M.P. Corry and S. Applebaum, 2007. Listening to mothers: Report of the second national US Survey of women's childbearing experiences. J. Perinat. Educ., 16: 15-17. DOI: $10.1624 / 105812407$ X244778
Friend, J.R. and V.V. Kakkar, 1970. The diagnosis of deep venous thrombosis in the puerperium. J. Obstet. Gynaecol. Br. Commonw., 77: 820-823. http://www.ncbi.nlm.nih.gov/pubmed/5458773

Fuantes, A., 1997. Labor and Delivery. In: Practical Guide to the Care of Gynecologic/Obstetrica Patients, Dallakas, T.G. and M. Pictrontani (Eds.). Mosby Missou, Mosby, ISBN: 0-8151-2316-7, pp: 412.

Hill, A., 2010. Cesarean section. http://www.childbirthsolutions.com/articles/birth/c esarean/index.php

Johnson, R., 1999. Dauharts's Textbook of Obstetric Procedure for Postgraduate. 6th Edn., WileyBlackwell, ISBN: 0865426511, pp: 622.

Koroukian, S.M. and A.A. Rimm, 2000. Comparison of Cesarean section versus vaginal delivery for post partum complication by type of delivery in the Ohio Medicaid population. http://gateway.nlm.nih.gov/MeetingAbstracts/ma?f $=102272723 . \mathrm{html}$

Lamisden, M.A. and M. Hideey, 2000. Complete Women's Health. 1st Edn., Royal College of obstetric and Gynecology, Thorsons, ISBN: 07225-34302, pp: 220.

Lydon-Rochelle, M., V.L. Holt, T.R. Easterling and D.P. Martin, 2000. First birth cesarean and placental abruption or previa at second birth. Obstet. Gynecol., 97: 765-769. http://cat.inist.fr $/$ ?aModele $=$ afficheN\&cpsidt $=9770$ 70

Miller, H.S., J. McEvers and J.A. Grift, 1997. Instructions for Obstetric and Gynecologic Patient. Delhi Book Store, New Delhi, Del, India, ISBN: 10: 0721673686, pp: 44.

Shearer, E.L., 1993. Cesarean section: Medical benefits and costs. Soc. Sci. Med., 37: 1223-1231. http://www.americanpregnancy.org/labornbirth/ces areanrisks.html 